\title{
Heterotopias, mundo comum e as bibliotecas públicas
}

Maria Aparecida Moura

Doutora em Comunicação e Semiótica pela PUC/SP. Professora Titular da Escola de Ciência da Informação

http://dx.doi.org/10.1590/1981-5344/2299

Este artigo propõe um estudo conceitual sobre as bibliotecas públicas em contexto brasileiro. Para isso, analisou-se o papel social das bibliotecas públicas no Brasil a partir dos conceitos de heterotopia de Foucault e de mundo comum, proposto por Arendt. Como principais resultados, chamou-se a atenção para a correlação potencial entre os conceitos de heterotopia e mundo comum na concepção de bibliotecas públicas e suas repercussões nas experiências e memórias afetivas dos usuários da Biblioteca Pública Mário de Andrade, em São Paulo (SP), e da Biblioteca Pública Estadual Luiz de Bessa, em Belo Horizonte (MG).

Palavras-chave: Bibliotecas públicas. Heterotopia. Mundo comum.

\section{Heterotopias, world common and public libraries}

This paper proposes a conceptual study about public libraries in Brazilian context. To do this, it was analyzed the social role of public libraries in Brazil from the concepts of heterotopia by Foucault and common world, proposed by Arendt. As main results, we draw attention to the potential correlation between the concepts of heterotopia and common world in the conception of public libraries and its impact on the experiences and the emotional memories of users of the public Library Mário de Andrade, São Paulo (SP), and the State Public Library Luiz de Bessa, Belo Horizonte (MG). 


\section{Keywords: Public libraries. Heterotopia. Common world.}

Recebido em Aceito 11.12.2014 Aceito em 12.12.2014

\section{Introdução}

“A condição humana compreende algo mais que as condiçães nas quais a
vida foi dada ao homem. Os homens são seres condicionados: tudo aquilo
com o qual eles entram em contato torna-se imediatamente uma condição de
sua existência."

(ARENDT, 1995, p. 17).

As bibliotecas públicas surgiram no século XIX na Inglaterra no contexto da revolução industrial. Em 1949, a instituição incorporou a função adicional de apoiar os processos educativos das camadas populares.

Alvo de constantes questionamentos, a ação das bibliotecas públicas oscilou entre a atenção às classes médias e a elite na década de 1950 e uma identificação explícita com os movimentos culturais contestatórios dos anos de 1960 e 1970.

A abordagem cultural, educacional e com foco no lazer apareceu no manifesto da UNESCO proposto em 1972.

Nas décadas de 1980 e 1990 acentuaram-se em âmbito internacional as mudanças tecnológicas. Em decorrência disso, as bibliotecas públicas passaram a incorporar de novo papel, de caráter comunicacional e tecnológico.

No Brasil a primeira biblioteca pública foi criada em 1811, na cidade de Salvador, Bahia. Em sua instituição em contexto nacional, a biblioteca pública já incorporava o propósito de apoiar educação.

De acordo com a Fundação Biblioteca Nacional (2000, p. 17) "as bibliotecas, em geral, são classificadas de acordo com as funções que desempenham, o tipo de leitor para o qual direcionam seus serviços e o nível de especialização de seu acervo." Entretanto, a recém-aprovada legislação estabelece o acesso universal às bibliotecas públicas no Brasil, impulsionou os debates sobre o conceito de bibliotecas públicas, o alcance e o sentido do acesso aos acervos público em âmbito nacional. De acordo com o projeto de lei aprovado (PLS 156/2013) biblioteca pública é definida como a instituição mantida integralmente pela União, estado ou municípios.

Nota-se na definição legal uma simplificação excessiva que limita o conceito aos marcos de sua manutenção. Desse ponto de vista, arrisca-se em restringir a potencialidade das bibliotecas públicas em processos sociais de "florescimento da cidadania".

É, pois, essencial, ao interpretar esses documentos, lembrar que eles visam estabelecer conceitos, princípios e valores de consenso internacional para a valorização da biblioteca pública. Foram elaborados com o objetivo de nortear políticas 
nacionais e divulgar conceitos e princípios gerais vigentes universalmente, num determinado momento histórico da sociedade. (FUNDAÇÃO BIBLIOTECA NACIONAL, 2000, p. 27).

Em face da diversidade conceitual que a concepção de biblioteca pública encerra, optou-se nesse texto por compreendê-la à luz de duas abordagens teóricas: heterotopia, de Michel Foucault (1967) e mundo comum, proposto por Hanna Arendt (1958). Buscou-se, desse modo,lançar luz à correlação potencial existente entre os referidos conceitos e as bibliotecas públicas em contexto nacional.

\section{Heterotopias e mundo comum}

\subsection{Heterotopias}

As Heterotopias são espaços concretos ou mentais organizados em torno de uma função em que se destaca o lugar da alteridade.

Parte integrante das dicotomias inultrapassáveis e invioláveis, assinaladas por Foucault, as bibliotecas compreendem em si dimensões utópicas e heterotópicas.

Do ponto de vista espacial, Foucault ressalta que a utopia refere-se a lugares que possuem uma relação analógica direta ou invertida com o espaço real da sociedade. Dessa perspectiva, a sociedade pode ser vista numa forma simultaneamente aperfeiçoada e irreal.

Em contraste ao conceito de utopia encontram-se as heterotopias que se caracterizam por serem,

Lugares reais e efetivos que são delineados na própria instituição da sociedade e que são espécie de contraposionamentos, espécies de utopias efetivamente realizadas nos quais os posicionamentos reais que se podem encontrar no interior da cultura estão ao mesmo tempo representados, contestados e invertidos, espécies de lugares que estão fora de todos os lugares, embora eles sejam efetivamente localizáveis. (FOUCAULT, 2006, p. 415).

As heterotopias se organizam em torno de seis princípios fundamentais:

- São próprias à cultura de todo e qualquer grupamento humano,

- Adotam funcionamentos distintos da heterotopia existente ou prévia,

- Agrega vários espaços ou posicionamentos que podem ser em si incompatíveis,

- Articulam diferentes temporalidades, 
- Possuem sistemas de abertura e fechamento que as isolam e/ou as tornam penetráveis,

- Possuem uma função relacionada ao seu entorno.

As heterotopias possuem uma função e criam espaços de ilusão ou novas realidades. De acordo com Foucault, as heterotopias se articulam nos seguintes tipos: de crise, de desvio, de tempo, crônicas e de compensação.

As heterotopias de crise caracterizam-se por lugares privilegiados, sagrados ou proibidos, destinados a indivíduos que se encontram, em crise, em relação à sociedade e ao meio humano. O comportamento manifesto em tais heterotopias devem se realizar em não lugares.

As heterotopias de desvio são destinadas a indivíduos que manifestam um comportamento desviante em relação à média ou à norma exigida. As casas de repouso, as clínicas psiquiátricas e as prisões apresentam-se como exemplos dessa dimensão heterotópica. A principal contradição da heterotopia de desvio refere-se ao fato de que ao integrála o sujeito torna-se excluído.

As heterotopias de tempo referem-se aos lugares que estão vinculados a momentos ou a parcelas de tempo. Os museus e bibliotecas destacam-se como exemplares heterotopias de tempo. Segundo Foucault,

São heterotopias nas quais o tempo não cessa de se acumular e de se encarapitar no cume de si mesmo, enquanto no século XVII, até o fim do século XVIII ainda, os museus e as bibliotecas eram expressão de uma escolha individual. Em compensação, a ideia de tudo acumular, a ideia de constituir uma espécie de arquivo geral, a vontade de encerrar em um lugar todos os tempos, todas as épocas, todas as formas, todos os gostos, a ideia de constituir um lugar de todos os tempos que esteja ele próprio fora do tempo, e inacessível à sua agressão, o projeto de organizar assim uma espécie de acumulação perpétua e infinita do tempo em um lugar que não mudaria, pois bem, tudo isso pertence à nossa modernidade. O museu e a biblioteca são heterotopias próprias à cultura do século XIX. (FOUCAULT, 2006, p. 419).

Através da genealogia dos equipamentos coletivos, compreendidos como heterotopias, é possível refletir sobre as práticas discursivas associadas aos espaços. Desse ponto de vista, Foucault relembra que,

não vivemos numa espécie de vazio que se encheria de cores com diferentes reflexos, vivemos no interior de um conjunto de relações que definem posicionamentos irredutíveis uns aos outros e absolutamente impossíveis de ser sobrepostos (FOUCAULT, 2006, p. 415).

As heterotopias crônicas referem-se aos equipamentos coletivos de caráter passageiro e transitório, tais como feiras, cidades de veraneio, 
campeonatos, congressos e festivais. Em geral essas heterotopias estão associadas ao festejo do tempo através da abolição de sua centralidade.

Finalmente, as heterotopias de compensação se referem à criação de espaços reais meticulosamente estruturados e que apontam para outros, considerados originais. Dentre as heterotopias de compensação destacam-se as colônias jesuítas que plasmaram no território colonizado o arranjo geográfico e funcional aperfeiçoado do ponto de vista do colonizador.

\subsection{Mundo Comum}

\footnotetext{
"Se o mundo deve conter um espaço público, não pode ser construído apenas para uma geração e planejado somente para os que estão vivos: deve transcender a duração da vida de homens mortais. Sem essa transcendência para uma potencial imortalidade terrena, nenhuma política, no sentido restrito do termo, nenhum mundo comum e nenhuma esfera pública são possíveis. (...) o mundo comum é aquilo que adentramos ao nascer e que deixamos para trás quando morremos. Transcende a nossa vida tanto no passado quanto no futuro: preexistia à nossa chegada e sobreviverá à nossa breve permanência”. (ARENDT, 1995, p. 64).
}

O conceito de mundo comum é central na obra de Arendt (KATTAGO, 2012, CUSTÓDIO, 2011). Para a filósofa, o mundo refere àquilo que é compartilhado publicamente pelos indivíduos. Desse ponto de vista, compreende a esfera pública (polis) como o domínio da pluralidade, da liberdade, do discurso e da ação. Salienta que na esfera pública são reveladas livremente nossas identidades.

No âmbito da obra de Arendt, Custódio (2011, p. 12) assinala que mundo pode ser considerado,

um conjunto de heranças simbólicas e materiais, produto das obras humanas, na medida em que é comum, ele se interpõe entre os homens, permitindo tanto a sua união, quanto a sua separação. Dessa forma o mundo é o artificialismo humano e o espaço de convivência onde os homens encontram-se e constituem, em comunidade, o significado de seus artefatos, feitos, palavras, histórias e memória comum. Em seus diversos aspectos, tal mundo comum revela-se à pluralidade humana como uma realidade tangível e compartilhada, possibilitando a permanência de obras e histórias humanas para além da vida de cada indivíduo.

A perspectiva apresentada por Arendt, acerca do mundo e da condição humana permite compreender os artificialismos produzidos pelo homem, inclusive os equipamentos coletivos, como possibilidade de nossa existência. Nesse sentido, as bibliotecas, e mais especificamente as bibliotecas públicas, compõem o mundo, na medida em que criam oportunidades para a expressão da pluralidade pela convivência em espaços públicos. No que concerne à esfera privada, Arendt assinala que,

para o individuo, viver uma vida inteiramente privada significa, acima de tudo, ser destituído de coisas essenciais à 
vida verdadeiramente humana: ser privado da realidade que advém do fato de ser visto e ouvido por outros, privado de uma relação "objetiva" com eles decorrentes do fato de ligarse e separar-se deles mediante um mundo comum de coisas, e privado da possibilidade de realizar algo mais permanente que a própria vida. A privação da privatividade reside na ausência de outros; para estes, o homem privado não se dá a conhecer, e portanto, é como se não existisse. O que quer que faça permanece sem importância ou consequência para os outros, e o que tem importância para ele é desprovido de interesse para os outros. (ARENDT, 1995, p. 68).

Para Arendt (1995, p. 15), as três atividades humanas fundamentais são o labor, o trabalho e a ação. O labor é uma condição fundamental da vida; o trabalho permite a transcendência das vidas individuais através da mundanidade e, finalmente, a ação revela as atividades individuais entre os homens que se realiza sem a "mediação das coisas ou da matéria".

Para Arendt a ação compartilhada e o discurso são elementos centrais que evidenciam que o homem é um ser no mundo. Desse modo, "Sempre que a relevância do discurso entra em jogo, a questão torna-se política por definição, pois é o discurso que faz do homem um ser político. (ARENDT, 1995, p. 11).

Kattago (2012, p. 105) relembra ainda que o discurso é inerentemente político porque é público e instaura o nosso mundo comum.

A pluralidade humana, condição básica da ação e do discurso, tem o duplo aspecto de igualdade e diferença. Se não fossem iguais, os homens seriam incapazes de compreender-se entre si e aos seus ancestrais, ou de fazer planos para o futuro e prever as necessidades das gerações vindouras. Se não fossem diferentes, se cada ser humano não diferisse de todos os que existiram, existem ou virão a existir, os homens não precisariam do discurso e da ação para se fazerem entender. (ARENDT, 1995, p. 188).

No mundo comum a singularidade humana se revela no discurso e na ação. Na medida em que,

no homem, alteridade, que ele tem em comum com tudo que existe, e a distinção, que ele partilha com tudo o que vive, tornam-se singularidade, e a pluralidade humana é a paradoxal pluralidade dos seres singulares. (ARENDT, 1995, p. 189). 
A biblioteca pública instaura-se como um espaço de convivência, compartilhamento e de tessitura da pluralidade humana e, qual o mundo comum proposto por Arendt, "sobreviverá à nossa breve permanência".

\section{Biblioteca pública, heterotopia e mundo comum: uma dimensão discursiva}

A Biblioteca é uma permanência interior e exterior. (BONOMI, 2006, p. 48, grifos nossos).

Compreender as bibliotecas públicas de uma perspectiva heterotópica e voltada ao mundo comum requer que se tome como referência a dimensão discursiva que orienta a sua constituição no contexto nacional.

De acordo com o manifesto da UNESCO (1994) a biblioteca pública é considerada a "porta de acesso local ao conhecimento - fornece as condições básicas para uma aprendizagem contínua, para uma tomada de decisão independente e para o desenvolvimento cultural dos indivíduos e dos grupos sociais."

\section{Manifesto da Biblioteca Pública}

\begin{tabular}{|l|l|}
\hline 1949 & $\begin{array}{l}1^{\text {a }} \text {. versão - Manifesto da Biblioteca Pública - foco no ensino e educação das } \\
\text { classes populares. }\end{array}$ \\
\hline 1972 & $\begin{array}{l}2^{\text {a }} \text {. versão - Manifesto da Biblioteca Pública - foco na educação, cultura, lazer } \\
\text { e informação. }\end{array}$ \\
\hline 1994 & $\begin{array}{l}3^{\text {a }} \text {. versão - Manifesto da Biblioteca Pública - Democratização do acesso às } \\
\text { novas tecnologias da informação }\end{array}$ \\
\hline
\end{tabular}

Fonte: Fundação Biblioteca Nacional. Coordenadoria do Sistema Nacional de Bibliotecas Públicas. Biblioteca Pública: princípios e diretrizes.

Do ponto de vista do referido manifesto, são missões das bibliotecas públicas: criar e fortalecer os hábitos de leitura nas crianças, desde a primeira infância; apoiar a educação individual e a autoformação, assim como a educação formal a todos os níveis; assegurar a cada pessoa os meios para evoluir de forma criativa; estimular a imaginação e criatividade das crianças e dos jovens; promover o conhecimento sobre a herança cultural, o apreço pelas artes e pelas realizações e inovações científicas; possibilitar o acesso a todas as formas de expressão cultural das artes do espetáculo; fomentar o diálogo intercultural e a diversidade cultural; apoiar a tradição oral; assegurar o acesso dos cidadãos a todos os tipos de informação da comunidade local; proporcionar serviços de informação adequados às empresas locais, associações e grupos de interesse; facilitar o desenvolvimento da capacidade de utilizar a 
informação e a informática e apoiar, participar e, se necessário, criar programas e atividades de alfabetização para os diferentes grupos etários.

Em consonância com o Manifesto da UNESCO, o Sistema Nacional de Bibliotecas Públicas - SNBP (2000, p. 17) compreende que essas instituições se baseiam,

na igualdade de acesso para todos, sem restrição de idade, raça, sexo, status social, etc. e na disponibilização à comunidade de todo tipo de conhecimento. Deve oferecer todos os gêneros de obras que sejam do interesse da comunidade a que pertence, bem como literatura em geral, além de informações básicas sobre a organização do governo, serviços públicos em geral e publicações oficiais. A biblioteca pública é um elo de ligação entre a necessidade de informação de um membro da comunidade e o recurso informacional que nela se encontra organizado e à sua disposição. Além disso, uma biblioteca pública deve constituir-se em um ambiente realmente público, de convivência agradável, onde as pessoas possam se encontrar para conversar, trocar ideias, discutir problemas, autoinstruir-se e participar de atividades culturais e de lazer.

Além disso, o SNBP (2000) reconhece que as mudanças tecnológicas trouxeram novos desafios no âmbito das bibliotecas públicas e ampliaram o seu escopo. Assim, no cenário nacional as bibliotecas públicas atuam também como: agente essencial na promoção e salvaguarda da democracia, através do livre acesso a todo tipo de informação proporcionando, desta forma, matéria de reflexão para a geração do verdadeiro conhecimento; instituição de apoio à educação e formação do cidadão em todos os níveis, através da promoção e incentivo à leitura e à formação do leitor crítico e seletivo capaz de usar a informação como instrumento de crescimento pessoal e transformação social; centro local de tecnologias da informação, através do acesso às novas tecnologias da informação e da comunicação, familiarizando os cidadãos com o seu uso e instituição cultural, através da promoção do acesso à cultura e do fortalecimento da identidade cultural da comunidade local e nacional.

Compreende-se que a informação que é transacionada nessas instâncias revela uma dimensão significativa da existência humana que apoia e norteia o estar em sociedade e a formação da visão de mundo (Weltanschauung), sensibiliza para a fruição dos registros criativos dos saberes e da cultura, engaja e orienta a ação individual e coletiva e permite a consolidação, o registro e o diálogo da pluralidade de saberes e conhecimentos.

Todavia, em que pese à abrangência do conceito de biblioteca pública proposto pelo manifesto da UNESCO e a ampliação incorporada pelo SNBP, a PLS 259/2013 insere um dispositivo na Lei n¹0. 753 de 30 
de outubro de 2003 no qual introduz novo conceito às bibliotecas públicas em território nacional. $\mathrm{Na}$ conceituação aprovada, ampliam-se as tipologias a ela anexadas e assinala-se o papel central do provedor. Assim, para efeitos legais as bibliotecas públicas brasileiras são compreendidas como,

todos os tipos de bibliotecas: pública, especializada, escolar, universitária, comunitária, infantil, digital, especial e nacional, mantidas total ou parcialmente com recursos da União, dos estados ou municípios.

Na PL 259/2013, assinala-se que a nova concepção é fruto de debate com o Conselho Federal de Biblioteconomia brasileiro e que a conceituação é aceita no mundo acadêmico e das bibliotecas.

Destaca-se, contudo, que a necessidade de fornecer amparo legal à concepção de biblioteca pública pode burocratizar a ação das bibliotecas e incorporar a essa heterotopia uma dimensão funcional que tende a reduzir a sua potencialidade em relaçãoà perspectiva de mundo comum.

Conforme ressalta Foucault apud Castro (2009, p. 119)

as práticas discursivas não são pura e simplesmente modos de fabricação de discursos. Elas tomam corpo no conjunto das técnicas, das instituições, dos esquemas de comportamento, dos tipos de transmissão e difusão, nas formas pedagógicas que, por sua vez, as impõem e as mantêm.

Indica-se, no entanto que, ao tomar como referência a nova concepção, as políticas públicas e os processos formativos delas decorrentes, tendem a sofrer um empobrecimento em sua ação na medida em que se reduz também o caráter de esfera pública exercido pelas bibliotecas.

\section{A função social das bibliotecas públicas: reverberações}

\footnotetext{
Nada substitui o contato real que você tem com a sua cidade quando você vai da sua casa à biblioteca e da universidade à biblioteca. (CHAUÍ, 2006, p. 11).
}

A função social das bibliotecas públicas é, ainda nos dias de hoje, razão de controvérsias e incompreensões no país.

A inserção de bibliotecas públicas no Brasil data de 1811, através dacriação da Biblioteca Pública do Estado da Bahia (BPEB), idealizada por Pedro Gomes Ferrão Castelo Branco, e instalada atualmente no bairro dos Barris em Salvador, Bahia. 
De acordo com o Sistema Nacional de Bibliotecas Públicas (SNBP), o Brasil conta hoje com6062 bibliotecas públicas ${ }^{1}$, sendo 5984 municipais, três federais, 45 estaduais e 30 distritais.

Atualmente, as bibliotecas públicas caracterizam-se por diferentes propostas políticas e por constantes alterações em suas diretrizes, devido, em grande parte, ao vínculo com distintas instâncias provedoras e diversificadas políticas públicas das quais são objeto.

Em que pese às distintas intervenções sofridas pelas bibliotecas públicas brasileiras ao longo da história de sua constituição, se reconhece que elas exercem um papel transformador na formação da cidadania cultural, na democratização da informação e na sensibilização dos sujeitos sociais em relação à arte e a cultura.

Tomando como referência o papel exercido pelas bibliotecas públicas, buscou-se perceber e destacar as evidências dos conceitos de heterotopia e mundo comum na atuação dessas instituições. Para tanto, buscou-se compreender tais evidências nas representações de usuários das bibliotecas públicas Mário de Andrade, de São Paulo, e Luiz de Bessa de Belo Horizonte. Com esse propósito, utilizaram-se os depoimentos oriundos do projeto Memória Oral, desenvolvido na ocasião da comemoração dos 80 anos da Biblioteca Pública Mário de Andrade²em 2005 e de entrevistas a usuários da Biblioteca Pública Luiz de Bessa, constantes na tese de doutorado intitulada "Biblioteca pública, identidade e enraizamento: elaborações intersubjetivas ancoradas em torno da Luiz de Bessa" de autoria de Fabrício José Nascimento da Silveira, publicada em 2014.

A Biblioteca Pública Mário de Andrade foi fundada em 1925, como Biblioteca municipal, e inaugurada como biblioteca pública em 1926. Essa biblioteca é considerada uma referência cultural no Brasil e na América Latina tendo sido criada em meio à ambiência sociocultural da Semana de Arte Moderna de 1922. Trata-se da segunda maior biblioteca Pública do Brasil, fruto da atuação visionária de Mário de Andrade e do Departamento de Cultura de São Paulo.

A Biblioteca Pública Estadual Luiz de Bessa, vinculada à Secretaria do Estado da Cultura, foi fundada pelo governador Juscelino Kubitschek em 02 de junho 1954. Em sua fundação, dentre as prioridades estavam o empréstimo domiciliar, o serviço de referência e o processamento técnico.

Com um processo de construção relativamente longo e polêmico, a Luiz de Bessa passou a ocupar o seu atual endereço em 1961. A biblioteca conta com projeto arquitetônico de Oscar Niemeyer e integra atualmente o circuito cultural Praça da Liberdade.

As duas bibliotecas selecionadas para a análise possuem um destacado papel na cena cultural do país, notadamente em São Paulo e Minas Gerais.

\footnotetext{
${ }^{1}$ Conforme informações disponíveis em: <http://snbp.bn.br/indicadores/dados-das-bibliotecas-publicas/>. Acesso em: 31 ago. 2014.

${ }^{2}$ Os depoimentos encontram-se disponíveis no

<http://www.prefeitura.sp.gov.br/cidade/secretarias/cultura/bma/memoria_oral/index.php?p=7962>. Acesso em: 31 ago. 2014.
} 
No que se refere ao caráter heterotópico das bibliotecas a antropóloga e usuária da Mário de Andrade, Ruth Cardoso, destacou o compromisso desse equipamento público com a cultura local e a sociabilidade que proporcionava para a sua geração.

Eu acho que a Biblioteca foi marcante para mim, mesmo antes de eu entrar na universidade. Eu fui educada no interior, fui criada em Araraquara, onde eu nasci, e eu vim para cá em 1946 para fazer o curso colegial. Então nesse período eu estava no colegial aqui, no colégio interno, mas tinha certa liberdade e, no fim de semana, a gente saía. Esta Biblioteca era um lugar de encontro, um lugar muito atrativo, porque, evidentemente, a gente circulava muito por toda essa parte da cidade e aqui era um lugar que a gente encontrava gente nova, gente diferente, que a gente vinha procurando. Então, eu tive muitos amigos, que eu fiz aqui nesta Biblioteca nessa época, mesmo antes da entrada na universidade (...)

Todo mundo vinha à Biblioteca. Nessa altura era bastante difícil você ter uma biblioteca particular suficiente para dar conta do que a gente precisava ler, e era também essa vida social, quer dizer, não é só porque aqui tinha os livros, mas era também porque havia esse movimento, da gente se encontrar e estudar aqui. Uma das coisas divertidas era que nós estudávamos e descobríamos os livros que o Florestan tinha lido porque ele anotava e a gente reconhecia a letrinha dele (CARDOSO, 2005, p. 1-4, grifos nossos).

A artista plástica Maria Bonomi, destaca a abertura para as indagações e contradições proporcionadas pela convivência no espaço social da biblioteca.

Aqui em São Paulo, onde eu estava, os lugares afetivos eram, evidentemente, a Biblioteca. A Biblioteca não era para mim nem um afeto, era uma obrigação porque eu fazia perguntas que ninguém podia responder, só a Biblioteca tinha o livro para essas respostas. Eu me lembro, até meus pais diziam: "Vai para Biblioteca". (BONOMI, 2006, p. 2, grifos nossos).

O Usuário da Biblioteca Estadual Luiz de Bessa, Lucas P., salienta em sua experiência o caráter heterotópico em relação à cultura e o potencial de salvaguarda do mundo comum representado pela biblioteca pública.

A Luiz de Bessa tem uma importância social, crucial pra vários jovens e adultos que estão em processos de seleções, pode ser concurso, vestibular, acho que essa importância é crucial. Eu sei também que é uma biblioteca que tem muita circulação de usuários no acervo geral, eu vejo isso, eu vejo muita circulação ali. Então é importante na difusão de leitura, na 
guarda do patrimônio cultural, de parte do patrimônio cultural já que uma instituição não é capaz de guardar todo o patrimônio cultural. (LUCAS P. apud SILVEIRA, 2014, p. 195, grifos nossos).

$\mathrm{Na}$ experiência da filósofa Marilena Chauí, tanto o caráter heterotópico quanto a preservação do mundo comum são potencializados pela ação das bibliotecas públicas e se destacam em sua memória afetiva como usuária da Biblioteca Mário de Andrade.

A Mário era, vamos dizer, a referência de um enorme e admirável mundo novo possível, sobretudo para uma adolescente vinda do interior. A descoberta desta Biblioteca, desde a descoberta dela, arquitetonicamente falando, que era de embevecer os olhos... Eu estou falando isso de 1956, 57, quando São Paulo tinha uma escala humana (...) Então se constituiu pra mim um mapa da cidade em cujo centro estava a Biblioteca Mário de Andrade. Ela era a minha referência cultural, minha referência geográfica, minha referência afetiva. A gente marcava encontro com os namorados aqui. Os grandes momentos de agitação cultural aconteciam aqui. (...) Então ela é uma referência fundamental. Ela era também de uma importância muito grande não só por que ela era o lugar onde a estudantada das escolas públicas do secundário e das universidades estavam, mas por que ela fazia parte também de um cenário cultural. (CHAUÍ, 2006, p. 2-3, grifos nossos).

Paul Singer, por seu turno, destaca as características heterotópicas dos sistemas de abertura e fechamento que encontravam ressonância no convívio e atuação política em um tempo de recrudescimento sóciopolítico em que a Biblioteca Mário de Andrade esteve também em cena.

A última, digamos, ligação mais intensa com a Biblioteca foi depois do golpe militar. O Partido Socialista, em 65 - eu era secretário-geral do partido aqui em São Paulo - ele foi dissolvido, como todos os partidos. Houve o Ato Institucional número 2, os partidos foram todos dissolvidos. Criaram-se o Arena e MDB. E aí nós criamos o Centro de Estudos João Mangabeira. E, para estrear esse centro - naquele momento a esquerda estava toda muito comprimida pela derrota e pela repressão, era uma coisa quase de frente única - a gente organizou um curso na Biblioteca que foi muito interessante. Colocamos uma série de problemáticas, desde o problema de raça, de religião. Era um curso cultural, mas com fundo político, evidentemente. (SINGER, 2008, p. 13, grifos nossos). 
Luiz Q., aponta para a transcendência, própria ao mundo comum, que os equipamentos públicos, tais como bibliotecas e museus, podem oportunamente refletir nas heterotopias de tempo.

A Luiz de Bessa é fundamental na cidade. Ela é a única biblioteca, até onde eu sei, ela é a única biblioteca aberta ao público com um acervo variado, não só de livros, mas também de jornais e de revistas. Você tem as bibliotecas universitárias, mas elas acabam não atendendo à mesma função que uma biblioteca pública deveria atender. Então eu acho que é fundamental, ela precisa existir, ela precisa continuar existindo. (LUIZ Q. apud SILVEIRA, 2014, p. 196, grifos nossos).

Em virtude dos princípios conceituais acima destacados, e tomandose como referência a reverberação do lugar social das bibliotecas públicas nas experiências e memórias afetivas dos usuários,tornou-se imprescindível aformalizaçãode planos formativos mais abrangentes para os profissionais que atuam em bibliotecas públicas.

Nesse âmbito, é também fundamental oestabelecimentode políticas públicas menos clivadas por transitoriedades políticas e, consequentemente mais comprometidas com o mundo comum.

Acredita-se que esses valores podem ser articulados em políticas públicas densas e ensejados em projetos eexperiências culturais concretas promovidas nas bibliotecas públicas.

\section{Considerações finais}

A análise de contexto que envolve as bibliotecas públicas no Brasil compreende necessariamente as instâncias de formação, os profissionais bibliotecários que atuam nesses contextos, as instituições de representação profissional e os formuladores de políticas públicas. Nesses termos, parece oportuno que tais atores sociais compreendam a pertinência de sua atuação em um mundo contraditório e heterotópico.

Conforme se destacou ao longo desta discussão, a heterotopia e o mundo comum são dimensões conceituais em que se destaca o lugar da alteridade, compreendida como pluralidade e singularidade humanas.

$\mathrm{Na}$ medida em que se reconhece que o discurso e a ação dos homens podem engendrar o mundo comum, assinalado por Arendt (1995) torna-se imprescindível a constante análise crítica dos discursos fundadores, dos dispositivos legais e da genealogia dos equipamentos coletivos. A compreensão de tais dimensões pode revelar uma vontade de memória e a afirmação pública da centralidade do mundo comum.

\section{REFERÊNCIAS}

ARENDT, Hannah. A condição humana. Rio de Janeiro: Forense Universitária, 1995. 
BONOMI, Maria. Registro audiovisual. Entrevista concedida a Sérgio Teichner e Daisy Perelmutter para o projeto Memória Oral da Biblioteca Mário de Andrade. Disponível em: <http://www.prefeitura.sp.gov.br/cidade/upload/transcricao_fhc_ruth_12 97178854.pdf>. Acesso em: 28 ago. 2014.

BRASIL. PLS 156/2013. Insere dispositivo na Lei no 10.753, de 30 de outubro de 2003, para promover o acesso universal às bibliotecas públicas. Disponível em: <http://www.senado.gov.br/atividade/materia/detalhes.asp?pcod_mate= $112531>$. Acesso em: 28 ago. 2014.

BRASIL. PLS 259/2013. Insere dispositivo na Lei no 10.753, de 30 de outubro de 2003, para estabelecer o conceito formal de bibliotecas públicas. $\quad$ Disponível em: <http://www.senado.gov.br/atividade/materia/getPDF.asp?t=131229\&tp $=1>$. Acesso em: 28 ago. 2014.

CARDOSO, Ruth. Registro audiovisual. Entrevista concedida a Eugênio Puppo e Daisy Perelmutter para o projeto Memória Oral da Biblioteca Mário de Andrade. São Paulo. Brasil. 22 mar. 2005. Disponível em: <http://www.prefeitura.sp.gov.br/cidade/upload/transcricao_fhc_ruth_12 97178854.pdf >. Acesso em: 28 ago. 2014.

CASTRO, Edgardo. Vocabulário de Foucault: um percurso pelos temas, conceitos e autores. Belo Horizonte: Autêntica, 2009.

CHAUÍ, Marilena. Registro audiovisual. Entrevista concedida a Sergio Teichner, Lúcia Neíza e Daisy Perelmutter para o projeto Memória Oral da Biblioteca Mário de Andrade. São Paulo. Brasil. 19 jul. 2006. Disponível em:

<http://www.prefeitura.sp.gov.br/cidade/upload/transcricao_marilena_ch aui_1297189488.pdf>. Acesso em: 28 de ago. 2014.

CUSTÓDIO, Crislei de Oliveira. Educação e mundo comum em Hannah Arendt: reflexões e relações em face da crise do mundo moderno. 2011. Dissertação (Mestrado em Educação)-Universidade de São Paulo, São Paulo, 2011. Disponível em: <http://www.teses.usp.br/teses/.../CRISLEI_DE_OLIVEIRA_CUSTODIO.pd f>. Acesso em: 20 maio 2014.

FOUCAULT, Michel. As palavras e as coisas: uma arqueologia das ciências humanas. 9. ed. São Paulo: Martins Fontes, 2007.

FOUCAULT, Michel. Outros espaços. In: FOUCAULT, Michel. Ditos e escritos. Rio de Janeiro: Forense Universitária, 2000. v. 3.

FREITAS, Marília Augusta de; SILVA, Vanessa Barbosa da. Bibliotecas públicas brasileiras: panoramas e perspectivas. Revista Digital de Biblioteconomia e Ciência da Informação, Campinas, v. 12, n. 1, p. 126146. jan./ abr. 2014. Acesso em: <www.sbu.unicamp.br/seer/ojs/index.php>. Acesso em: 20 jul. 2014. 
FUNDAÇÃO BIBLIOTECA NACIONAL. Coordenadoria do Sistema Nacional de Bibliotecas Públicas. Biblioteca Pública: princípios e diretrizes. Rio de Janeiro: Fundação Biblioteca Nacional, Dep. de Processos Técnicos, 2000.

KATTAGO, Siobhan. How common is our common world?: Hannah Arendt and the rise of social. Problemos, v. 81, p. 98-108, 2012. Disponível em: <http://www.vu.It/leidyba/dokumentai/zurnalai/PROBLEMOS/Problemos\% 202012\%2081/98-108.pdf>. Acesso em: 17 ago. 2014.

MANIFESTO DA IFLA/UNESCO SOBRE BIBLIOTECAS PÚBLICAS - 1994. Disponível em: <http://archive.ifla.org/VII/s8/unesco/port.htm>. Acesso em: 17 ago. 2014.

RIBEIRO, Alexsander Borges. Bibliotecas públicas do Brasil: passado, presente e futuro. Monografia (Graduação em Biblioteconomia)Universidade Federal do Rio Grande do Sul. Porto Alegre, 2008. Disponível em:

<http://www.lume.ufrgs.br/bitstream/handle/10183/17857/000718838.p df? sequence $=0>$. Acesso em: 17 ago. 2014.

SÃO PAULO. Prefeitura de São Paulo. Secretaria Municipal de Cultura. Biblioteca Mário de Andrade. Disponível em: <http://www.prefeitura.sp.gov.br/cidade/secretarias/cultura/bma/>. Acesso em: 28 ago. 2014.

SILVEIRA, Fabrício José Nascimento da. Biblioteca pública, identidade e enraizamento: elaborações intersubjetivas ancoradas em torno da Luiz de Bessa. 253f. 2014. Tese (Doutorado em Ciência da Informação)-Belo Horizonte, Universidade Federal de Minas Gerais, 2014.

SILVEIRA, Fabrício José Nascimento da. Memória e mediações sociais: a história da Biblioteca Mário de Andrade (BMA) contada através de relatos de vida. In: JORNADA CIENTÍFICA INTERNACIONAL DA REDE MUSSI, 2., 24-26 out. 2012, Rio de Janeiro, FIOCRUZ, 2012. p. 213-228.

SINGER, Paul. Registro audiovisual. Entrevista concedida a Sergio Teichner e Daisy Perelmutter para o projeto Memória Oral da Biblioteca Mário de Andrade. Disponível em: <http://www.prefeitura.sp.gov.br/cidade/upload/transcricao_paul_singer_ 1297190892.pdf>. Acesso em: 28 ago. 2014.

SISTEMA NACIONAL DE BIBLIOTECAS PÚBLICAS - SNBP. Disponível em: <http://snbp.bn.br/>. Acesso em: 28 ago. 2014. 